\title{
LINGUAGEM E SOCIO-HISTÓRIA AFRO-BRASILEIRA: DESAFIOS À FORMAÇÃO CONTINUADA
}

Lilian do Rocio Borba

Universidade Estadual de Campinas

\section{Resumo:}

O objetivo central deste artigo é dialogar com professores que buscam subsídios em pesquisas acadêmicas para ancorar suas práticas relativas à história e à cultura afro-brasileira e africana. A pesquisa insere-se nas discussões sobre a formação socio-histórica do português brasileiro sob o viés do contato linguístico. Argumenta-se em favor de que, ao abordar esta temática, é necessário considerar a atuação do negro africano e de seus descendentes como indivíduos falantes e participantes ativos na construção da identidade linguística do Brasil. Os objetivos específicos compreendem a abordagem de: 1) aspectos socio-históricos sobre a formação do português no Brasil, 2) questões sociolinguísticas relacionadas a falares africanos na constituição do português brasileiro; 3) questões de língua e identidade sob o viés histórico. A discussão tem como base estudos relevantes no âmbito da sociolinguística histórica, os quais evidenciam que o português brasileiro, no que se diferencia do português europeu, é fruto das relações sociais que se desenvolveram (e ainda se desenvolvem) em nosso país desde o período colonial, assinalando que mais que influência africana em uma lista de palavras, o contato entre negros africanos ou descendentes - índios e portugueses forjou a identidade linguística brasileira.

Palavras-chave: formação português brasileiro - história e cultura afrobrasileira - formação continuada professores 


\title{
Language and socio-african-Brazilian history: challenges for continuing education
}

\begin{abstract}
:
The central purpose of this article is to dialogue with teachers who seek academic research grants to anchor their practices relating to the history and african-Brazilian and African culture. The research is part of the discussions about the socio-historical development of the Brazilian Portuguese language contact on the bias. We argue in favor of that, in addressing this issue, it is necessary to consider the role of the African and his descendants black speakers as individuals and active participants in the construction of linguistic identity of Brazil. Specific objectives include the approach: 1) socio-historical data on the formation of the Portuguese in Brazil, 2) sociolinguistic issues related to African dialects in the constitution of the Brazilian Portuguese aspects; 3) issues of language and identity in the historical bias. The discussion is based on material in the context of historical sociolinguistic studies, which show that Brazilian Portuguese, which differs in European Portuguese, is the fruit of social relations that developed (and even thrive) in our country since the colonial period, noting that more than African influence in a word list, the contact between blacks Africans or descendants - Indians and Portugueses forged linguistic identity.
\end{abstract}

Keywords: Brazilian Portuguese; african-Brazilian history and culture; continuing education teachers 


\section{Introdução}

Um dos desafios teóricos e metodológicos colocados nos última década à formação continuada docente diz respeito à implementação da Lei no 10.639/03 que orienta sobre o ensino da História da África e Cultura Afro-brasileira. Segundo a lei, o conteúdo programático deve incluir o estudo da História da África e dos africanos, a luta dos negros no Brasil, a cultura negra brasileira e o negro na formação da sociedade nacional, resgatando a contribuição do povo negro nas áreas social, econômica e política pertinentes à História do Brasil. Essa decisão resgata historicamente a contribuição dos negros na construção e formação da sociedade brasileira. Mesmo já havendo disciplinas relacionadas, sobretudo à História da África, à literatura de matriz africana que fazem parte dos currículos dos cursos de Pedagogia e Letras, por exemplo, há ainda um importante caminho a se trilhar na formação continuada docente. $\mathrm{O}$ objetivo central deste trabalho é dialogar com professores que buscam subsídios em pesquisas acadêmicas para ancorar suas práticas sobre a temática acima colocada. Os objetivos específicos compreendem a abordagem de:

- Aspectos socio-históricos sobre a formação do português no Brasil;

- Aspectos sobre as relações entre brancos e negros no Brasil colonial;

- Questões socio-linguísticas relacionadas a falares africanos na constituição do português brasileiro;

- Questões sobre língua e identidade sob o viés histórico.

\section{Breve história sobre a formação do português brasileiro}

Nosso idioma, a língua portuguesa, como se sabe, não nasceu no Brasil. Com origens no Latim, o português foi implantado no continente sul-americano em decorrência da colonização portuguesa, que oficialmente se inicia em 1500. Fruto das grandes Olh@res, Guarulhos, v. 2, n. 2, p. 227-254. Dezembro, 2014. 
navegações e do comércio e domínio português, além de Portugal e do Brasil, a língua portuguesa é utilizada em países de outros continentes (Figura 1). Na África: em Cabo Verde, Guiné Bissau, São Tomé e Príncipe, Angola e Moçambique. Na Ásia: Timor Leste, Goa e Macau.

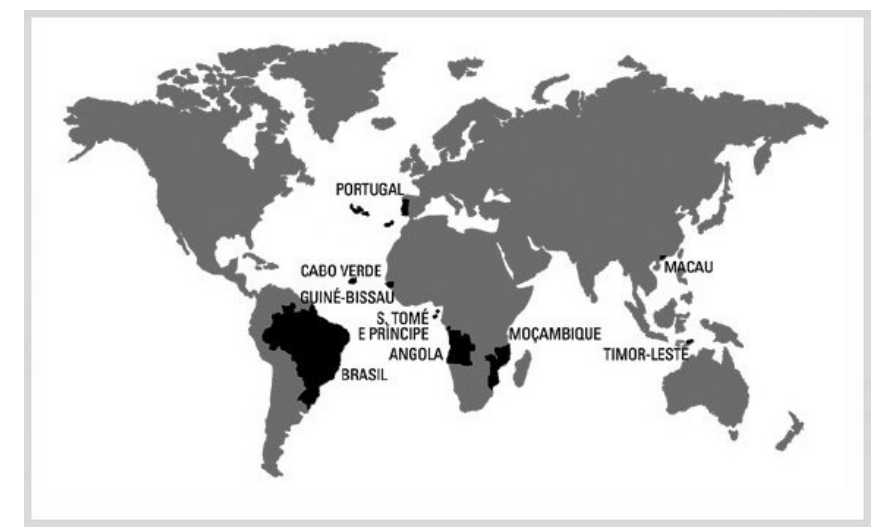

Figura 1 - A língua portuguesa no mundo Fonte: http://cvc.institutocamoes.pt/cpp/acessibilidade/imagens/mapa01.jpg

Naturalmente, em lugares e continentes tão diferentes, cada uma dessas versões da língua portuguesa tem suas características próprias. Durante o período colonial - quando o Brasil ainda não era o Brasil - o português foi a língua usada na administração portuguesa da colônia e nos contatos com a metrópole; foi a língua do governo e da Justiça e, mais tarde, a língua da literatura. No entanto, ao se considerar as condições do povoamento do futuro país, sabe-se que por um longo período que se inicia no Brasil-Colônia e prossegue até o tempo do rei e do Império, o país conviveu com os falares nativos e os falares africanos. (Cf.: ILARI \& BASSO, 2006, p 62). Nessa seção, vamos refletir um pouco sobre essa história.

\subsection{A matriz indígena}

Quando os portugueses aqui chegaram, em 22 de abril de 1500, batizaram o que seria futuramente o Brasil de Terra de Vera Cruz e nomearam índios aos habitantes que nestas terras encontraram. Mattos e Silva (2004) conta-nos parte dessa história, ao mencionar 
trecho da carta de Pero Vaz de Caminha, em que o escrivão de Cabral explica ao rei por que ficariam na terra recém-descoberta dois degredados além de dois grumetes que haviam fugido da frota que seguiria para as Índias:

Esses quatro primeiros semeadores do português no Brasil aqui ficaram antes para aprenderem "a sua fala"(fol. 11, ls 26-30), a dos índios, e assim convertêlos e não para ensinar-lhes português; quanto à terra, não seria ela mais que "pousada pêra esta navegaçonm de Calecut" (fol. 13v, ls. 22-27) (MATTOS e SILVA, 2004, p14)

Como frisa a autora, os portugueses aprenderam a língua dos índios com o intuito de convertê-los ao cristianismo e com esses quatro semeadores da língua portuguesa que aqui ficaram inicia-se a trajetória de dizimação dos índios brasileiros e de suas línguas iniciada pelos primeiros colonizadores portugueses e que prossegue até nossos dias. Na época do descobrimento, já vivia no Brasil uma população indígena estimada em 6 milhões de pessoas, falantes de, aproximadamente, 1.175 línguas (Cf.: RODRIGUES, 1993). Os portugueses precisaram aprender a língua dos indígenas para sua própria sobrevivência, pois eram os índios quem melhor conhecia. a terra, quem sabia onde encontrar alimento, caçar e navegar pelos rios. Outro forte motivo para os portugueses aprenderem a língua dos índios era para impor seu domínio aos nativos. Uma das formas de domínio empregadas foi a catequização imposta aos índios e que foi efetuada pelos padres da Companhia das Índias.

Os jesuítas, como informa Mattos e Silva (2004: 77), tinham como princípio de catequese usar as línguas da terra em que chegavam. Fazia parte de seu programa catequético no Brasil dominar a(s) língua(s) local(is). A língua dos índios Tupinambá era falada no século XVI sobre uma enorme extensão da costa atlântica (do litoral de São Paulo ao litoral do Nordeste). Ao longo dos séculos XVI, XVII e XVIII, o Tupinambá foi chamado também de língua do Brasil, língua da terra (isto é, da terra do Brasil), língua do mar (isto é, a língua falada na costa, junto ao mar) e língua brasílica tornando-se uma das línguas mais difundidas durante o período colonial (cf.: 
RODRIGUES, 1986: 99-101). Os religiosos empenhados na catequese organizaram gramáticas e dicionários das línguas utilizadas entre índios, portugueses e seus descendentes. Em 1595, o padre jesuíta José de Anchieta teve publicada a primeira dessas obras, a sua Arte de gramática da língua mais usada na Costa do Brasil.

Esses breves elementos históricos nos ajudam a perceber que o ambiente linguístico do Brasil colonial foi marcado pelo multilinguismo generalizado, ou seja, diversas línguas e povos em contato falando línguas de bases indígenas, paralelamente ao uso do português em contextos oficiais (documentos e órgãos públicos). Outro aspecto que merece atenção é que falantes africanos e descendentes também utilizavam as línguas gerais. Foi em 1757 que, através da Lei do Diretório, o Marquês de Pombal instituiu a obrigatoriedade do uso da língua portuguesa no Brasil e expulsou os jesuítas - a Companhia das Índias - um dos alicerces do uso e da difusão das línguas gerais.

A imposição da língua portuguesa através do decreto do Marquês de Pombal $^{1}$ foi uma das medidas que visavam, segundo Boris Fausto (1995), contar com uma população nascida no Brasil identificada com os objetivos lusos, o que asseguraria o controle de vastas regiões semidespovoadas. A expulsão dos padres jesuítas foi uma medida política importante para Portugal, pois os jesuítas constituíam áreas de atuação autônoma cujos fins eram diversos dos objetivos da Coroa. Pode-se dizer que enquanto a finalidade dos jesuítas era catequizar por meio da língua geral, a finalidade da Coroa era colonizar, sob o argumento de civilizar por meio da linguagem: o uso da língua portuguesa. O decreto que impõe o uso da língua portuguesa associado a outras medidas políticas - houve também as econômicas - mostra claramente como a ideia de língua nacional neste ato se relaciona com a ideia de civilização.

E, por meio desse processo histórico e político de constituição da língua que utilizamos hoje no Brasil, a presença de 
palavras de origem indígena se apresenta como um de nossos traços linguísticos característicos. Podemos citar os nomes de frutas (caju, pitanga) e de animais encontrados no Brasil (jararaca, urubu, sabiá) além de muitos outros termos de uso corrente em nossa língua contemporânea, cuja origem é indígena: piracema, pororoca, igarapé, catapora, curupira, arapuca. Vale exemplificar também alguns dos muitos topônimos: Ceará, Goiás, Maranhão, Pará, Pernambuco, Piauí, Paraná, Paraíba, Niterói, Corumbá.

\subsection{A matriz africana}

Muito embora os indígenas tenham sido os primeiros povos escravizados no Brasil no período da colonização, foram os africanos e seus descendentes que representaram a mão-de-obra escrava por excelência, utilizada nas atividades produtivas (agricultura, pecuária, mineração etc.) e na prestação de serviços rurais e urbanos (serviçais domésticos, vendedores de rua, marinheiros, sapateiros, marceneiros, trabalhadores na construção civil etc.), até a extinção do sistema escravocrata em 1888 (ALKMIM, 2008).

Desde o início da colonização, por volta de 1550 até o fim do tráfico em 1850, atravessaram o Atlântico em direção ao Brasil cerca de 5 milhões de indivíduos vindos de diferentes regiões da África na condição de escravizados, falantes de diversas línguas (aproximadamente 300). Dentro desse universo de línguas e de povos diferentes, vieram para o Brasil, predominantemente, falantes escravizados de duas regiões subsaarianas: a região banto, localizada ao longo da extensão sul da linha do Equador e a região oeste-africana ou sudanesa, que abrange territórios que vão do Senegal à Nigéria. Importante destacar que ao tratarmos do continente africano é fundamental pensarmos em diversidade de línguas, grupos étnicos. Vejamos abaixo (Figura 2) o mapa político da África atual²: 


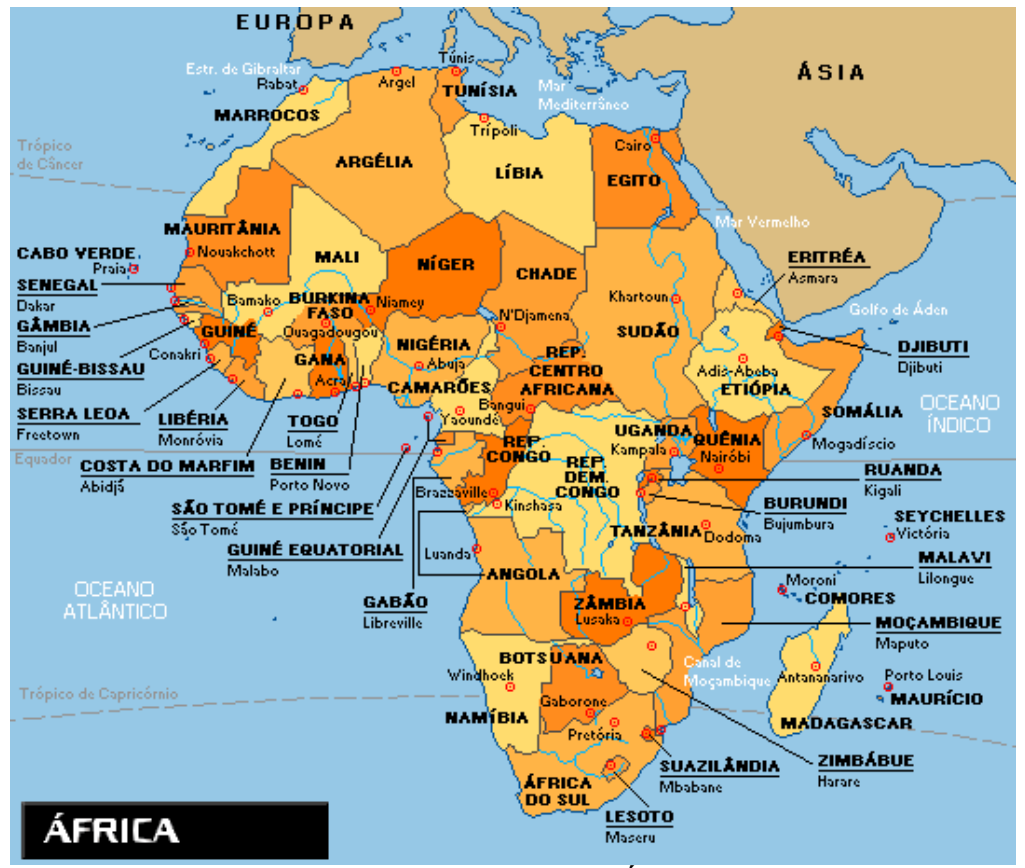

Figura 2: Mapa político da África. Fonte:

http://www.infoescola.com/geografia/africa/

As línguas da região banto compõem um grupo de mais de 500 línguas semelhantes, faladas em 21 países da África subequatorial: Camarões, Chade, República Centro-Africana, Guiné Equatorial, Gabão, Angola, Namíbia, República Popular Congo (Brazzaville), República Democrática do Congo (RDC ou CongoKinshasa), Burundi, Ruanda, Uganda, Tanzânia, Quênia, Malavi, Zâmbia, Zimbábue, Botsuana, Lesoto, Moçambique, África do Sul. Entre elas, as de maior número de falantes no Brasil foram três línguas angolanas, a saber quicongo, também falada no Congo, quimbundo e umbundo. (PESSOA DE CASTRO, s/d)

Quanto às línguas oeste-africanas ou sudanesas, seus principais representantes no Brasil foram os povos de línguas do grupo ewe-fon vindos de Gana, Togo e Benim, conhecidos como minas ou jejes, e os iorubas da Nigéria e do reino de Queto (Ketu), estes últimos na vizinha República do Benin, onde são chamados de nagôs. (PESSOA DE CASTRO, s/d:)

Impressiona a diversidade de línguas e de povos existentes no extenso território africano e é importante ressaltar que apesar de 
escutarmos e lermos conceitos ligados à África no singular - cultura africana, civilização africana - este é um continente culturalmente rico onde são faladas atualmente em torno de 1,5 mil idiomas entre as cerca de 800 etnias ou povos.

A herança africana que está presente nos vários aspectos da vida brasileira se forjou em virtude da forma de vida que havia no Brasil no período colonial. As relações sociais existentes no Brasil colonial promoveram o contato entre falantes de línguas diferentes transformando o português vindo de Portugal em uma língua com características próprias. Os censos, sobretudo a partir do século XVII, revelam que a população de africanos e de seus descendentes era numericamente superior ao número de europeus durante três séculos consecutivos.

\begin{tabular}{|c|c|c|c|c|c|}
\hline & $\begin{array}{c}1538- \\
1600\end{array}$ & $\begin{array}{c}1601- \\
1700\end{array}$ & $\begin{array}{c}1701- \\
1800\end{array}$ & $\begin{array}{c}1801- \\
1850\end{array}$ & 1850 \\
\hline Africanos & $20 \%$ & $30 \%$ & $20 \%$ & $12 \%$ & $2 \%$ \\
\hline Negros brasileiros & - & $20 \%$ & $21 \%$ & $19 \%$ & $13 \%$ \\
\hline Mulatos & - & $10 \%$ & $19 \%$ & $34 \%$ & $42 \%$ \\
\hline $\begin{array}{c}\text { Brancos } \\
\text { brasileiros }\end{array}$ & - & $5 \%$ & $10 \%$ & $17 \%$ & $24 \%$ \\
\hline Europeus & $30 \%$ & $25 \%$ & $22 \%$ & $14 \%$ & $17 \%$ \\
\hline Índios integrados & $50 \%$ & $10 \%$ & $8 \%$ & $4 \%$ & $2 \%$ \\
\hline
\end{tabular}

Quadro 1: Dados organizados por Mussa (1990) apud Mattos e Silva (2004: 18)

Considerando os dados do Quadro 1, acima, podemos observar que a população de europeus nunca ultrapassou os $30 \%$ do total da população residente no Brasil. Sendo assim, a primeira conclusão apontada por diversos estudiosos (MATTOS e SILVA, 2004; ILARI \& BASSO, 2006) é que a ocupação do território brasileiro, embora tenha sido realizada em nome da Coroa Portuguesa, foi feita na realidade por uma população não-branca, sobretudo de origem africana.

Olh@res, Guarulhos, v. 2, n. 2, p. 227-254. Dezembro, 2014. 
Isso [essa expansão] se aplica à ocupação da costa brasileira, às várias bandeiras que partiam de São Paulo (com o propósito de aprisionar índios ou de encontrar minerais preciosos), à formação das cidades mineiras durante o ciclo do ouro e posteriormente, às migrações devidas ao ciclo da borracha. Em outras palavras, a conquista do território brasileiro deve ser atribuída, em grande parte, aos dois segmentos da população que não tinham ascendência portuguesa: o negro e o índio. (ILARI \& BASSO, 2006, p 76)

E, por meio dessa conquista territorial ligada aos ciclos econômicos pelos quais o país em formação foi passando, a língua falada pela população negro-mestiça foi chegando aos diversos cantos do território. Em outras palavras, o componente negro-mestiço ${ }^{3}$ foi o principal agente propagador da língua utilizada no país.

Os indivíduos que foram trazidos à força durante três séculos para o Brasil eram falantes de línguas africanas e aqui foram obrigados a aprender o português como segunda língua sem nenhuma instrução formal. Como lembram Ilari \& Basso (2006:77), o BrasilColônia teve poucas escolas, poucos livros e poucos letrados, por isso os portugueses mais ricos, sobretudo a partir do século XVIII, temendo que seus filhos não herdassem os estímulos da honra, mas os costumes dos negros e gentios, passaram a enviá-los para estudar em Portugal - na cidade de Coimbra - de onde retornavam com o título de bacharel em Direito. Pode-se refletir sobre que variedade de língua é falada em uma 'sociedade' formada por uma pequeníssima parcela de bacharéis e milhares de analfabetos convivendo: certamente não seria a variedade ligada à cultura letrada.

\subsubsection{Os bantos}

Dentre as línguas africanas que influenciaram o português brasileiro, a influência banta é a mais profunda em decorrência da antiguidade do povo banto - chamado também de congo-angola - no Brasil, da grande quantidade de indivíduos trazidos à força dessa região africana e da amplitude da distribuição desse povo em território

$3\urcorner$ A designação negro-mestiço refere-se aos descendentes dos contatos entre europeus, indígenas e africanos nascidos no território brasileiro na época da colonização.

Olh@res, Guarulhos, v. 2, n. 2, p. 227-254. Dezembro, 2014. 
brasileiro. Veja o mapa da distribuição de povos elaborado por Pessoa de Castro (2005)

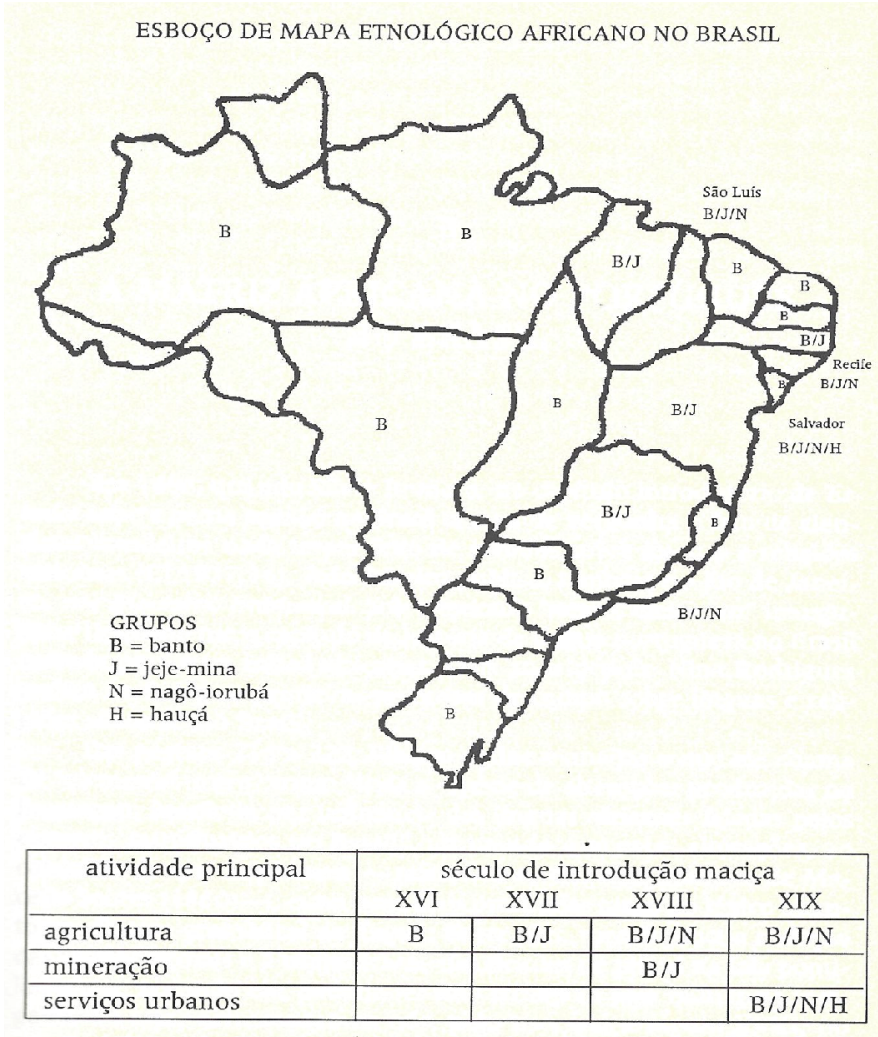

Figura 3: Fonte: PESSOA DE CASTRO, 2005, p. 47

Grande parcela dos falantes de línguas banto no Brasil utilizavam, sobretudo, três línguas angolanas: quicongo, também falada no Congo, quimbundo e umbundo. Como explica Pessoa de Castro(s/d: 71), os aportes bantos ou bantuísmos

\begin{abstract}
estão associados ao regime da escravidão (senzala, mucama, banguê, mocambo) sendo a maioria deles completamente integrada ao sistema linguístico do português, formando derivados portugueses a partir de uma mesma raiz banto (esmolambado, dengoso, sambista, xingamento, molequeira, caçulinha, quilombola), o que já demonstra uma antiguidade maior. ( PESSOA DE CASTRO, s/d: 72)
\end{abstract}

Destaca a autora também que em alguns casos os vocábulos de origem banto substituem o equivalente em português sem que nós, falantes, percebamos a origem africana da palavra. Vejamos no box alguns exemplos dessa substituição.

Olh@res, Guarulhos, v. 2, n. 2, p. 227-254. Dezembro, 2014. 


\begin{tabular}{||l|l|}
\hline Vocábulo português & Vocábulo banto \\
\hline \hline aguardente & cachaça \\
\hline benjamim & caçula \\
\hline bilha & moringa \\
\hline dormitar & cochilar \\
\hline giba & corcunda \\
\hline insultar & xingar \\
\hline nádegas & bunda \\
\hline óleo de palma & dendê \\
\hline sinete & carimbo \\
\hline trapo & molambo \\
\hline
\end{tabular}

Considerando esses bantuísmos, é importante destacar o uso da palavra caçula por ser a mais comum utilizada pelos brasileiros para se referir ao filho mais novo. Fato que como ressalta Pessoa de Castro (2005) fortalece a tese da influência sociolinguística da mulher negra, no papel servil de mãe preta, na intimidade da família colonial. Segundo a autora, essa influência também explicaria a razão de ser do ditado "o caçula é o dengo da família", ou seja, "o filho mais novo é cheio de manhas, recebe mais atenção'. Na frase, merece destaque também o vocábulo de origem banta dengo do quicongo/quimbundo, ndenge > dengue que entre outras acepções significa "manha, criancice, cólera infantill". No Brasil, a variante dengue é utilizada também com outra acepção: “doença transmitida por insetos”. Ambas as variantes ( dengo e dengue) são termos do português brasileiro cuja descendência é da língua banto.

\subsubsection{Os oeste-africanos}

Além dos povos de origem banto trazidos ao Brasil e já estabelecidos nos núcleos coloniais, é marcante também a chegada, no século XVIII, dos povos ewen-fon cujo número foi aumentando como consequência da demanda por mão de obra escrava nas minas de ouro e diamante, descobertas em Minas Gerais, Goiás e Bahia, paralelamente à produção de tabaco na região do Recôncavo baiano. (PESSOA de CASTRO, s/d)

Olh@res, Guarulhos, v. 2, n. 2, p. 227-254. Dezembro, 2014. 
Conforme a autora, em Vila Rica, Minas Gerais, a concentração de negros provenientes da costa oeste da África foi tanta que um falar de base ewe-fon foi registrado entre 1731 e 1741 por Antônio da Costa Lisboa no livro A obra nova da língua geral de mina, publicado apenas em 1945, em Lisboa. Esse documento linguístico é considerado o mais importante da história da escravidão no Brasil, uma vez que há pouquíssimas fontes históricas escritas para se reconstruir o cenário dos falantes de línguas africanas no país. O objetivo de tal documento, segundo seu autor, era ensinar aos garimpeiros o vocabulário, as frases e as expressões correntes entre a população escrava local, para evitar e reprimir rebeliões, fugas, furtos e contrabandos.

Pessoa de Castro (s/d: 72) chama a atenção para o fato de os povos oeste terem sido trazidos para o Brasil em um momento mais tardio, tendo ocorrido grande concentração de seus falantes em Salvador, sendo assim:

os aportes do ioruba são mais aparentes, especialmente porque são facilmente identificados pelos aspectos religiosos de sua cultura e pela popularidade dos seus orixás no Brasil (Iemanjá, Xangô, Ogum, Oxossi, etc). Por isso mesmo, a investigação sobre culturas africanas no Brasil tem sido baseada nos mais proeminentes candomblés de tradição nagô-queto em Salvador(...) que terminou por desenvolver a tendência de interpretar os aportes africanos no Brasil através de uma óptica ioruba mesmo quando não o são.

No final do século XVIII, a cidade de Salvador passa a receber grandes e sucessivas levas de povos procedentes da Nigéria atual, como consequência de guerras interétnicas na região. Entre o contingente, a presença nagô-iorubá foi tão significativa que o termo nagô na Bahia começou a ser usado indiscriminadamente para designar qualquer indivíduo ou língua de origem africana no Brasil.

2. Alguns aspectos sobre as relações entre brancos e negros no Brasil colonial

Olh@res, Guarulhos, v. 2, n. 2, p. 227-254. Dezembro, 2014. 
O Brasil no período colonial foi pouco povoado e vivia em um ambiente de isolamento, pois até 1808 - data da chegada da família real ao Rio de Janeiro e da abertura dos portos às nações amigas - só podia comercializar com Portugal. Nesse ambiente isolado em que a família colonial brasileira vivia, o negro escravizado teve papel fundamental. Um dos papéis que merece ser destacado sobre a atuação do negro na vida colonial foi o tráfico de influências exercido pelo escravo ladino - aquele que por aprender a falar rudimentos de português podia influir sobre um número maior de ouvintes, por participar de dois grupos social e linguisticamente diferenciados: os senhores habitantes da casa-grande e os escravizados habitantes das senzalas ${ }^{4}$. Enquanto na casa grande tais escravos eram os preferidos para o serviço doméstico, fazendo parte da intimidade familiar, "nas senzalas a eles era confiado o poder da disciplina e do comando que se estendia às plantações e aos engenhos na qualidade de capitães do mato e guardas pessoais de seus proprietários, com cujos interesses se identificavam". (PESSOA de CASTRO, s/d) Os ladinos adaptavam uma língua à outra e estimulavam a propagação de fenômenos linguísticos entre os não-bilingues, tanto da casa grande quanto da senzala.

Merece destaque também a atuação da mulher negra que desempenhava diversos papéis servis no círculo da família colonial: mãe preta, ama de leite (PESSOA de CASTRO, 2005); mucama, cozinheira, contadora de história (CUNHA-HENKEL, 2005, pp. 6367) - para citar algumas das funções domésticas. Eram as cantigas das chamadas mães de leite que embalavam o sono das crianças brancas, eram as histórias ouvidas de seus ancestrais que distraíam as crianças. É importante ressaltar que figuras como mãe de leite, mãe negra são construções brancas sobre o papel de mulheres negras na história das relações étnico-raciais no Brasil e que precisam ser analisadas sob uma ótica crítica, pois tais construções ou imagens não correspondem com a imagem que esses sujeitos e seus descendentes fazem sobre 
esses papéis. Cunha-Henkel (2005, pp. 64-65) em seu trabalho sobre os africanismos de origem banto na obra de José Lins do Rego, traz uma série de relatos da infância do autor que ajudam a observar um pouco dessas relações:

Africana também de Angola, andava de muletas, pois quebrara uma perna fazendo cabra cega para brincar com os meninos. Fora ama de braço de meu avô, e todos nós a chamávamos de vovó. Eu vivia de conversa com ela atrás de suas histórias da costa da África. E nos ensinava uns restos de palavras que ela ainda sabia de sua língua. (CUNHA-HENKEL, 2005, pp. 64-65)

Esse relato ilustra um pouco a face perversa da escravidão e as dicotomias das relações pois a ama de braço era chamada de vovó, mas andava de muletas por ter quebrado a perna brincando com os meninos. Que tipo de brincadeiras quebra a perna de pessoas? Note-se também a expressão restos de palavra, extremamente pejorativa, que inferioriza o falar africano da mulher escravizada. $\mathrm{O}$ compositor Chico César atualiza criticamente essa imagem das mães de leite, na canção Mama África:

$$
\begin{aligned}
& \text { Mama África, tem } \\
& \text { Tanto o que fazer } \\
& \text { Além de cuidar neném } \\
& \text { Além de fazer denguim } \\
& \text { Filhinho tem que entender } \\
& \text { Mama África vai e vem } \\
& \text { Mas não se afasta de você... }
\end{aligned}
$$

O compositor retrata a mulher negra que tem diversos afazeres e que cuida de nenéns, que faz dengos - nos filhos de outros. Essa é uma imagem atual que critica a construção de um dos papéis da mulher negra na família colonial brasileira.

Importante citar também, entre os papéis do negro na vida íntima da família colonial, a figura do moleque - vocábulo de origem banto que significa 'menino', mas que era utilizado com o sentido de 'filho de escravos'. Cunha-Henkel (2005, p. 66) traz outro exemplo extraído da obra de José Lins do Rego, referida acima, e que ilumina o que caracterizamos como relações sociais que propiciaram a interinfluência linguística. Como explica a autora, os moleques eram os filhos dos negros que, geralmente, eram criados junto com os filhos 
dos brancos da casa-grande. A autora dá voz a José Lins do Rego, que vivenciou essa situação:

O interessante era que nós, os da casa-grande, andávamos atrás dos moleques. Tudo eles sabiam fazer melhor do que a gente; soltar papagaio, brincar de pião, jogar castanha. Só não sabiam ler. Mas isto, para nós, também não parecia grande coisa. Queríamos viver soltos, com o pé no chão e a cabeça no tempo, senhores da liberdade que os moleques gozavam a todas as horas." (...) "Pelo caminho o moleque continuava nas suas lições, falando de mulheres e de doenças-do-mundo. (CUNHA-HENKEL, 2005, p. 66)

Mas Gilberto Freyre [(1933) 2002] também trata dessa relação que não se dava de maneira tão romântica entre escravizados e filhos de senhores - os yoyôs e yayás:

[o] muleque companheiro de brinquedo do menino branco e seu leva pancadas (...)apertado, maltratado e judiado como se fosse todo de pó de serra por dentro; de pó de serra e de pano como os judas de sábado de aleluia, e não de carne como os meninos brancos. (...) o melhor brinquedo dos meninos de engenho de outrora: montar a cavalo em carneiros; mas na falta de carneiros, muleques. Nas brincadeiras, muitas vezes brutas, dos filhos dos senhores de engenho, os muleques serviam para tudo: eram bois de carro, eram cavalos de montaria, eram bestas de almajarras, eram burros de liteiras e de cargas as mais pesadas. Mas principalmente cavalos de carro. [FREYRE (1930) 2002, p. 391]

A passagem explicita como o indivíduo escravizado era tomado por objeto e é difícil imaginar que tal relação não desenvolvesse no ser ou no grupo escravizado o esforço para se livrar do cativeiro. Risério (2007:326-332) traz uma interessante discussão sobre as formas e manobras empregadas pelos escravizados para se livrar desse estado. Chamada pelo autor de pequenas sedições do cotidiano $^{5}$ que denunciam a permanente revolta do sujeito escravizado ante as condições de vida imperantes no país, o autor trata da mentira e do engodo empregados pelos escravizados para induzir o senhor ao erro; trata ainda do envenenamento executado "homeopaticamente" também contra o senhor. Além de outros "gestos soberanos da vontade, na história do escravismo" tais como o suicídio de escravos, o aborto executado pelas próprias escravizadas para que seus filhos não tivessem o mesmo destino no cativeiro, além do furto, da fraude no garimpo, da fuga...enfim manobras, gestos, fatos que evidenciam a luta dos escravizados para a conquista da liberdade.

57 Risério (2007) utiliza a expressão empregada por Alípio Goulart (1972) em Da de fuga ao suicídio: aspectos da rebeldia dos escravos no Brasil.

Olh@res, Guarulhos, v. 2, n. 2, p. 227-254. Dezembro, 2014. 


\section{Domínios e níveis de integração dos aportes africanos no Brasil}

Os quatro séculos de contato permanente de falantes africanos e seus descendentes com a língua portuguesa no Brasil constituíram o idioma que utilizamos. Nesta seção veremos traços de permanência de línguas africanas no português do Brasil, como por exemplo nos falares de comunidades rurais povoadas por descendentes de ex-escravizados, que apresentam elementos de léxico de línguas africanas, e nas línguas de santo, utilizadas nos cultos afroreligiosos de diferentes nações encontradas em todo o território brasileiro. Em seguida, apresentaremos uma importante pesquisa sobre a estabilidade e o dinamismo de vocábulos de origem africana no português brasileiro.

\subsection{Domínios}

Pessoa de Castro (s/d: 73) afirma que o processo de interação linguística, apoiado por fatores favoráveis de ordem sóciohistórica e cultural foi possivelmente facilitado pela proximidade relativa da estrutura linguística do português europeu antigo com as línguas negro-africanas que o constituíram.

Entre essas semelhanças estão o sistema de sete vogais orais (a,e, ê, i, o, ô, u) e a estrutura silábica ideal (CV.CV - consoante-vogal.consoante-vogal), onde se observa a conservação do centro vocálico de cada sílaba e onde não haja sílabas terminadas em consoante. Essa semelhança estrutural provavelmente precipitou $\mathrm{o}$ desenvolvimento interno da língua portuguesa $\mathrm{e}$ possibilitou a continuidade da pronúncia vocalizada do português antigo na modalidade brasileira (onde as vogais átonas também são pronunciadas), afastando-a, portanto, do português de Portugal com pronúncia muito consonantal, o que dificulta seu entendimento por parte do ouvinte brasileiro, fazendo parecer tratar-se de outra língua que não a portuguesa. (confira a pronúncia brasileira de *pi.neu, *a.di.vo.ga.do, *su.bi.ma ri.no*ri.ti.mo, em lugar de pneu, ad.vo.ga.do, rit. mo) ( PESSOA de CASTRO, s/d: 73)

E o principal agente desse processo foi o negro banto que por sua antiguidade, volume populacional e amplitude territorial

Olh@res, Guarulhos, v. 2, n. 2, p. 227-254. Dezembro, 2014. 
devido à sua presença no Brasil colonial, recebeu o português como segunda língua, tornando-se o principal agente transformador da língua portuguesa em sua modalidade brasileira e, como dito anteriormente, seu principal difusor pelo território brasileiro sob o regime colonial e escravista. Pode-se encontrar ainda hoje diversos dialetos de base banto falados como línguas especiais por comunidades negras da zona rural, como afirma Pessoa de Castro (s/d: 73), provavelmente remanescentes de antigos quilombos em diversas regiões brasileiras. A comunidade do Cafundó, situada a doze quilômetros do município de Salto do Pirapora, que está a trinta quilômetros de Sorocaba e a, aproximadamente, 150 quilômetros da cidade de São Paulo, é um exemplo de remanescentes de quilombo cujos membros utilizam a língua do Cafundó: um vocabulário de origem banto com a estrutura gramatical do português (VOGT \& FRY, 1996).

Outro exemplo de remanescentes de quilombo é a comunidade de Bom Despacho, em Minas Gerais. No estudo Pé preto no barro branco; A língua dos Negros na Tabatinga a pesquisadora Sônia Queiroz coletou e organizou dados linguísticos, históricos e socioantropológicos referentes a essa comunidade. Segundo a autora (1998, p.30), o fato de ter a mineração intensificado o tráfico de escravos negros provenientes da Costa da Mina, no Golfo de Benin, e as ligações de Bom Despacho com uma vila do ouro - Pitangui sugerem uma origem sudanesa para a língua chamada de negro da costa. No entanto, os dados linguísticos coletados pela pesquisadora indicam uma predominância banta. Língua do negro da Costa significaria, segundo a autora, língua de africanos, o que se confirmaria por outros nomes que ela recebe de seus falantes em Bom Despacho: gíria dos cativero e língua cuete (“língua do homem”).

Tais comunidades, exemplos de resistência cultural, manifestam a maciça presença da matriz de línguas banto no território brasileiro à qual assentaram-se aportes ewe-fon e do iorubá, menos extensos e mais localizados, embora igualmente significativos para o processo de síntese pluricultural brasileira, sobretudo no domínio da Olh@res, Guarulhos, v. 2, n. 2, p. 227-254. Dezembro, 2014. 
religião. (PESSOA de CASTRO, s/d: 73) As línguas de santo linguagem de aspecto religioso e sagrado utilizada por várias comunidades afro-brasileiras em suas práticas litúrgicas - figuram como um domínio cujo repertório linguístico compreende um vocabulário específico de caráter simbólico, que tem por base sistemas lexicais de línguas africanas do tempo da escravidão no Brasil. Vejamos o exemplo do vocábulo candomblé analisado por Pessoa de Castro (2005: 82):

Candomblé, do banto kandómbilé > kandombélé, ação de rezar, pedir pela intercessão de (os deuses), derivado do verbo kudomba > kulomba, rezar, invocar, está empregado com o sentido corrente que toma entre seus seguidores. Designa os grupos sócio-religiosos dirigidos por uma classe sacerdotal, cuja autoridade suprema é popularmente chamada de mãe-de-santo ou pai-desanto, mas que recebe o título genérico de rumbondo ou rumbono (étimo fon), entre as nações jeje-mina; respectivamente de ialorixá ou babalorixá (étimo iorubá), entre nações nagô-gueto; e de nêngua ou tata (étimo banto), entre nações congo-angola. (PESSOA de CASTRO, 2005, p. 82)

Tal terminologia faz referência à organização sócioreligiosa do grupo, a cantigas, preces, objetos sagrados, saudações, expressões relacionadas à cozinha ritualística, aos costumes tradicionais e aos ritos litúrgicos, cujos seguidores a dominam, demonstrando uma competência simbólica mais do que linguística, isto é, para os fiéis o que mais importa durante as práticas é saber, por exemplo, em que momento deve ser entoada uma cantiga e não o significado literal da cantiga. O uso desses termos de acordo com a sua procedência africana determina a distinção das religiões afrobrasileiras entre nações, tais como jeje-mina, nagô-queto, congoangola, ou seja, respectivamente, de raízes ewe-fon, ioruba e banto.

\subsection{Níveis de integração de vocábulos africanos}

Alkmim \& Petter (2008) analisaram a estabilidade e o dinamismo de palavras de origem africana em uso nos dias de hoje partindo dos níveis propostos por Pessoa de Castro (2005). Uma das 
características deste estudo que merece destaque é o fato de as autoras terem acompanhado o registro desses vocábulos em dicionários $\mathrm{e}$ obras dos séculos $\mathrm{XIX}^{6}$ ao século XXI. As pesquisadoras observaram a manutenção e eventuais mudanças de significado de tais vocábulos, bem como avaliaram sua integração e vitalidade no português brasileiro, além de evidenciar sua historicidade. As autoras organizaram os dados coletados em três categorias:

Categoria 1: inclui termos que podem ser usados em qualquer interação social, contrastando com outras duas categorias.

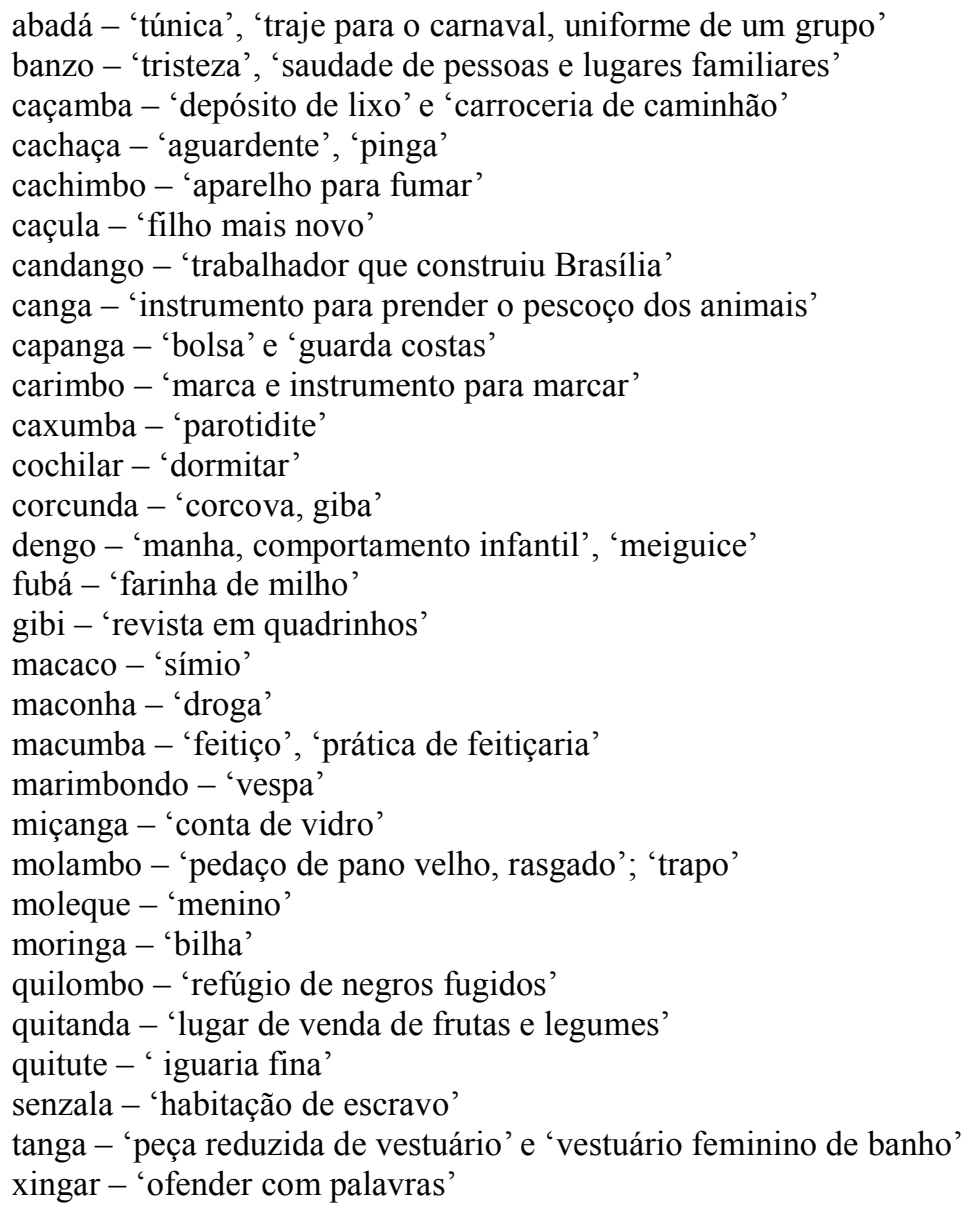

6 BEAUREPAIRE-ROHAN, Visconde e. Dicionário de vocábulos brasileiros. 2 ed. Salvador:Livraria progresso. (1956[1889])BORBA. Francisco S. Dicionário de usos do português do
Brasil.
São
Paulo:
Ática.
(2002)

FERREIRA, Aurélio Buarque de Holanda. Novo Aurélio Século XXI: o dicionário da língua portuguesa. 3 ed. Rio de Janeiro: Nova Fronteira. 1999

HOUAISS, Antônio. Dicionário Houaiss de língua portuguesa. Rio de Janeiro: Objetiva. 2001.

MACEDO SOARES, A. J. de. Dicionário brasileiro da língua portuguesa. Rio de janeiro: MEC/INL, 2v.(1954-1955 [1875-1888])

MENDONÇA, Renato. A influência africana no português do Brasil. 4ed. Rio de janeiro: Civilização brasileira. (1973 [1933])

RAIMUNDO, Jacques. O elemento afro-negro na língua portuguesa. Rio de Janeiro: Renascença. 1933.

Olh@res, Guarulhos, v. 2, n. 2, p. 227-254. Dezembro, 2014. 
Segundo as autoras, os termos dessa categoria encontramse perfeitamente integrados ao léxico brasileiro, o que se pode constatar pela capacidade de criação lexical que manifestam ao produzir compostos e derivados, como, por exemplo, xingar, e que se formariam xingamento, xingação, xingo, xingador, xingatório, xingado (cf. Borba, 2002). Tais termos constituem, na visão das autoras, o núcleo de resistência dos termos de origem africana do português brasileiro, embora pouca memória dessa origem tenha permanecido em muitos itens (carimbo, cochilar, entre outros).

As autoras chamam a atenção para os únicos termos não citados por nenhum dos trabalhos nos séculos XIX e XX, que são abadá e gibi. Conforme explicam, este último termo teve seu primeiro registro em Pessoa de Castro (2001), sob a forma JIBI, de étimo fon (wí)wívi 'negrinho'. Gibi foi o nome de uma revista semanal em quadrinhos, publicada pela primeira vez em 1939, que trazia na capa o desenho de um garoto negro. Na época o termo significava 'moleque, negrinho', com o tempo, a palavra passou a ser associada a revistas em quadrinhos e tornou-se sinônimo desse tipo de publicação. Já o termo abadá teve seus primeiros registros nos anos 1970, com base em Luís da Câmara Cascudo, com o significado de 'túnica branca que os negros malês (muçulmanos de origem africana) vestem para as preces noturnas'.

Categoria 2: Constituída de termos informais, de uso coloquial que, eventualmente, dependendo da situação, são substituídos por outros. Podem modificar-se mais rapidamente para atender a necessidades expressivas particulares.

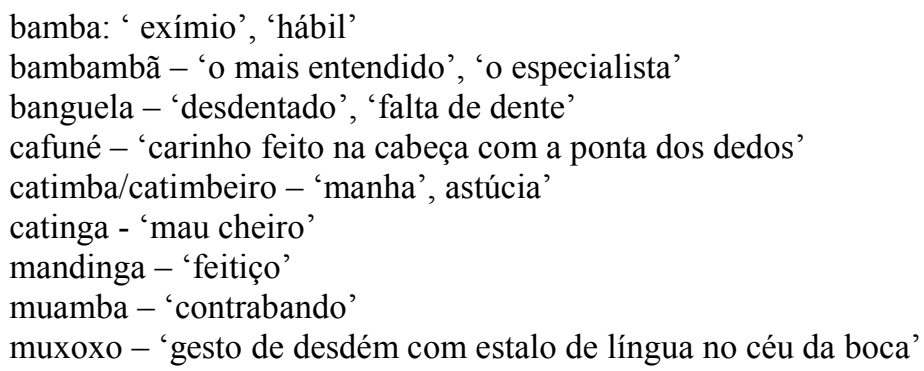

Foram incluídos nessa categoria itens que, segundo as autoras (2008, p.172), "manifestam um uso mais coloquial e que 
concorrem como sinônimos de valor próximo, porém menos marcados pela informalidade“. Como exemplos, bamba e bambambã seriam formas equivalentes a 'especialista, conhecer e o maior especialista e o grande conhecedor' e 'o melhor de todos'; banguela, 'desdentado, sem dentes'; cafuné, 'carinho na cabeça'; catimba (catimbeiro),' manha astúcia, malícia'; catinga, ' mau cheiro';mandinga, 'feitiço'; muamba, 'contrabando'; muxoxo, 'bico'. As autoras afirmam que, mesmo estes vocábulos estando integrados ao léxico geral, pois produzem termos derivados (catimbeiro, muambeiro, por exemplo), estão mais sujeitos à substituição por termos menos marcados pela informalidade.

Categoria 3: em que constam termos marcadamente informais, de uso restrito.

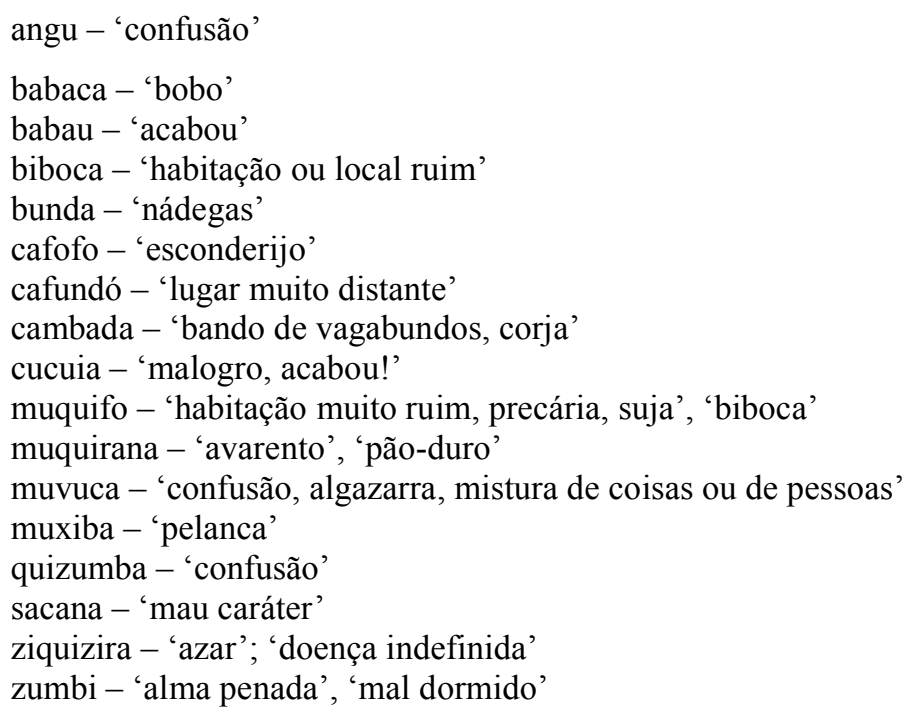

Essa é a categoria que, segundo as autoras, demonstra um dinamismo vigoroso, pois "novos termos nela entram e dela saem constantemente; alguns permanecem por um período em uso intenso, depois podem desaparecer" (2008, p.173), por isso, apresentam uma dinâmica diferente das categorias anteriores. As autoras encontraram 11 termos que não foram documentados no século $\mathrm{XX}$ por Raimundo e Mendonça - são eles: babaca, bababu, biboca, cafofo, cucuia, muquirana, тиvиса, quizumba, sacana e ziquizira - muito embora alguns tenham sido registrados no século XIX por Macedo Soares e Beaurepaire-Rohan: biboca, cafofo, muquirana, quizumba e sacana. A

Olh@res, Guarulhos, v. 2, n. 2, p. 227-254. Dezembro, 2014. 
reflexão das autoras sobre o fato gira em torno de algumas explicações possíveis: o não reconhecimento por parte dos pesquisadores Mendonça e Raimundo; o desaparecimento momentâneo do uso; os estudiosos não os teriam anotado, simplesmente; os vocábulos teriam sido de uso restrito a camadas sociais ou a regiões específicas; ou ainda, os sentidos atuais desses vocábulos seriam de integração recente ao léxico do português brasileiro tendo então escapado à documentação dos estudiosos.

Um exemplo interessante exposto pelas autoras é o caso do vocábulo тиvиса, introduzido pela mídia. Em 1997 foi o nome de um programa televisivo apresentado por Regina Casé, que pretendia ser um lugar onde culturas, personalidades e gostos diversos se misturassem, para justificar a explicação dada pelos produtores para o programa, 'reunião entre amigos'. Segundo as autoras, nas obras de referência, o item lexical aparece identificado como gíria, significando 'grande aglomeração de pessoas, confusão'. Em outros contextos identificados pelas autoras aparece 'lugar pequeno, esconderijo, enfusca, maloca, moquifo', sendo inclusive nomes de blogs. É comum ser utilizado também como nome de revista, bar, clube de futebol e comunidades virtuais. (ALKMIM \& PETTER, 2008, p.174).

Dentre as conclusões, as autoras ressaltam que muitos dos vocábulos de origem africana no português brasileiro desapareceram da língua falada e outros tantos são em geral desconhecidos ou de uso restrito. Muitos termos estão relacionados com a escravidão, nomeando realidades específicas ao sistema escravista brasileiro permanecendo como marcos da história: por exemplo, libambo 'corrente usada para prender escravos e prisioneiros'; quilombo 'povoação fortificada dos negros fugidos do cativeiro'. Outros vocábulos caíram em desuso como é o caso de caxirenguengue 'faca velha, sem cabo' e munganga 'careta, trejeito'; alguns talvez pela alternância com termos equivalente, às vezes até de origem africana mesmo: quigombô - quiabo; liamba/diamba/riamba - maconha.

\section{Refletindo sobre língua e identidade}

Olh@res, Guarulhos, v. 2, n. 2, p. 227-254. Dezembro, 2014. 
Considerando esse breve painel histórico sobre a formação do português brasileiro, cujo foco foi a presença de povos e línguas africanas na constituição do nosso idioma e a apresentação de pesquisas sobre os domínios e os níveis de integração dos aportes de origem africana, para finalizar esse trabalho, gostaríamos de refletir um pouco sobre língua, preconceito e construção de identidades.

O Brasil passa a figurar como um país "majoritariamente de língua nem indígena e nem africana" apenas a partir da segunda metade do século XVIII em decorrência do já mencionado Decreto do Marquês de Pombal. Até então se falavam no Brasil as línguas gerais, um pouco de português em situações oficiais, por uma população composta por um número cada vez menor de africanos, de indígenas, e de portugueses, tomando direção inversa o crescimento do número de mulatos e de brancos, verdadeiramente brasileiros.

Tanto a miscigenação quanto o decréscimo da presença de portugueses são indicadores favoráveis à formação de uma língua geral brasileira que não seria africana - por questões como a obrigatoriedade do uso do português na escola e nos documentos oficiais, por exemplo - nem indígena, mas "continuadora" do português já que os índios que seriam o terceiro vértice do triângulo, ou já tinham sido dizimados, ou integrados ou fugidos para confins protegidos. Implantada então em novo ambiente social, caracterizado pelo contato entre populações de línguas e culturas distintas, a língua portuguesa falada no Brasil não poderia deixar de se diferenciar daquela falada em Portugal. Como mostram diversos autores, entre os quais estão Zilles (2002), Mattos e Silva (2004) e Alkmim (2008), há outros aspectos importantes da história social brasileira que influenciaram a formação da nossa variedade do português, entre eles:

- Um sistema de escolarização extremamente precário e insuficiente (ausente em certos momentos) para a população livre em geral - e vedado a escravos - responsável pelo altíssimo índice de analfabetismo durante todo o período colonial Olh@res, Guarulhos, v. 2, n. 2, p. 227-254. Dezembro, 2014. 
- Um tardio processo de urbanização que, apesar de ter se iniciado entre o fim do século XVII e o início do século XVIII, consolidouse efetivamente apenas no começo do século XIX, particularmente com a chegada da família real portuguesa em 1808.

A ineficiência do sistema de educação formal e a ausência da pressão de uma norma linguística socialmente valorizada, irradiada de centros urbanos, têm sido vistas como fatores importantes na constituição do português brasileiro, determinantes de suas características e sua natureza. Para Zilles (2002, p.153), “imposta a língua portuguesa sem garantir os meios para a sua efetiva aprendizagem parece ter sido (e continua sendo) receita perfeita para ela [a língua] ser instrumento de exclusão social”. Daí para o preconceito linguístico, que estigmatiza a fala popular até hoje é um passo só. $\mathrm{O}$ século $\mathrm{XX}$, junto com a República, traz um Brasil cuja população é praticamente analfabeta, estigmatizada por não falar 'corretamente' o português. População concentrada no campo formada, ainda segundo Zilles (2002), “de múltiplas etnias, falantes de muitas línguas e também de muitas variedades do português”.

Segundo Faraco (2002, pp. 43-4), o debate sobre a língua do Brasil começou há mais de um século e meio e, desde então, recrimina o brasileiro por não utilizar corretamente sua língua. Mas, ainda conforme o autor, a variedade padrão ou a norma-padrão no Brasil foi construída de forma extremamente artificial, pois a elite letrada conservadora se empenhou em fixar como nosso padrão um certo modelo lusitano de escrita, praticado por alguns escritores portugueses do Romantismo. Ou seja, nosso modelo em termos de língua padrão não foi $a$ ou uma língua de Portugal, mas uma variedade literária de Portugal. Continuando, Faraco (2002) observa que além dessa herança excessivamente conservadora calcada no normativismo, está também o desejo daquela elite de viver num país branco e europeu, o que a fazia lamentar o caráter multirracial e mestiço do nosso país (...) e, no caso da língua, a fazia reagir sistematicamente contra tudo aquilo que nos diferenciasse de um certo padrão linguístico lusitano. Assim abrasileirar o idioma significava Olh@res, Guarulhos, v. 2, n. 2, p. 227-254. Dezembro, 2014. 
corromper, degenerar, deturpar a língua portuguesa. Abrasileirar o idioma significava se aproximar da língua utilizada pelo vulgo, ou seja, da população mestiça, de ascendência africana de quem a elite queria se afastar.

Christino (2001) observa que nos anos 1920, a discussão dos intelectuais sobre língua passava por discussões sobre raças que formavam o caldeamento no Brasil. Mas as contribuições tinham estatutos diferenciados. A variedade popular não era considerada língua, mas deturpação, ou seja, as variedades tinham o valor que seus usuários tinham na sociedade. Para revelar o fosso existente entre a linguagem dos brancos e a dos não-brancos, a autora mostra que português de 'gente branca' podia valer como sinônimo de 'bom português'. (2001, p. 223)

A identidade cultural não é algo em si, um fato social pronto e sempre igual, a ser mobilizado sempre que necessário, ao contrário, será sempre uma construção de algo que pode nos distinguir do outro, segundo o momento histórico vivido.

Nesse sentido, conhecer e valorizar a história da formação e da constituição de nossa língua e de seus falantes é um importante fator para a afirmação de nossa identidade brasileira, mestiça, que é fruto dos (des)encontros entre índios, portugueses, africanos e toda gama de seus descendentes. Gostaríamos de dar, mais uma vez, voz a etnolinguista Pessoa de Castro(s/d: 73) que desde a década de 1960 estuda a presença de falares africanos no português do Brasil:

(...) o português do Brasil, naquilo que se afastou do português de Portugal é, historicamente, o resultado de um movimento implícito de africanização do português e, em sentido inverso, de aportuguesamento do africano sobre uma matriz indígena pré-existente e mais localizada no Brasil. Assim sendo, o português brasileiro descende de três famílias linguísticas: a família indo-europeia, que teve origem entre a Europa e a Ásia, da qual faz parte a língua portuguesa; a família das línguas tupi, faladas pelos indígenas brasileiros, que se espalha pela América do Sul; e, por fim, a família das línguas Níger-Congo, que teve origem na África subsaariana e se expandiu por grande parte desse continente.

Como consequência, povos indígenas e povos negros construíram junto com a cultura do colonizador português, que se estabeleceu no Brasil, uma nova variação da língua portuguesa: mestiça, brasileira.

Olh@res, Guarulhos, v. 2, n. 2, p. 227-254. Dezembro, 2014. 


\section{Referências Bibliográficas}

ALKMIM, Tânia. Língua portuguesa: objeto de reflexão e de ensino. Coleção Linguagem e Letramento em Foco. BRASIL.MEC: Ministério da Educação. Cefiel/IEL/Unicamp. 2008. no prelo.

ALKMIM, Tânia; PETTER, Margarida. Palavras da África no Brasil de ontem e de hoje. In: FIORIN, José Luiz e PETTER, Margarida. (org) África no Brasil, a formação da língua portuguesa. São Paulo: Contexto. 2008

CÉSAR, CHICO. Mama África. CD In: . Coleção Millenium. Polygram. Faixa 20.1998

CHRISTINO, Beatriz Protti. "Português de gente branca". Certas relações entre língua e raça na década de 1920. Dissertação de Mestrado. Departamento de Linguística, Universidade de São Paulo, São Paulo. 2001

CUNHA-HENKEL, Rosa. Tráfego de palavras. Africanismos de origem banto na obra de José Lins do Rego. Recife; Fundaj. Ed Massangana. 2005

FARACO, Carlos Alberto. Norma-padrão brasileira: Desembaraçando alguns nós. In: BAGNO, Marcos (org.) Linguística da norma. São Paulo. Edições Loyola.2002. p 3761.

FAUSTO, Boris. História do Brasil. $2^{\mathrm{a}}$ ed. São Paulo: Editora da Universidade de São Paulo: Fundação do Desenvolvimento da Educação. 1995

FREYRE, Gilberto. Casa Grande \& Senzala. Introdução à história da sociedade patriarcal no Brasil. 46a ed.Rio de Janeiro/São Paulo: Record. [2002.(1933)]

ILARI, Rodolfo; BASSO, Renato. O português da gente. A língua que estudamos, a língua que falamos. São Paulo: Contexto. 2006 
MATTOS E SILVA, Rosa Virgínia. Ensaios para uma sócio-história do português brasileiro. São Paulo: Parábola Editorial. 2004.

PESSOA DE CASTRO, Yeda. Falares africanos na Bahia. (Um vocabulário afrobrasileiro). $2^{\mathrm{a}}$ ed. Rio de Janeiro: Topbooks. 2005.

- Línguas africanas mudam o Brasil. In: Revista Entrelivros, textos fundamentais para ler e guardar: Vozes da África. São Paulo: Ediouro/Duetto. s/d

\section{A influência das línguas africanas no português brasileiro.} $<$ http://www.smec.salvador.ba.gov.br/documentos/linguas-africanas.pdf $>$. Acessado em 30/06/2014. s/d

QUEIROZ, Sônia Maria de Melo. Pé preto no barro branco: a língua dos negros da Tabatinga. Belo Horizonte: Ed. UFMG. 1998.

RISÉRIO, Antônio. A utopia brasileira e os movimentos negros. São Paulo: Ed. 34. 2007

RODRIGUES, Aryon Dall'igna. Línguas brasileiras. Para o conhecimento das línguas indígenas. São Paulo: Edições Loyola. 1986

. Línguas indígenas. 500 anos de descobertas e perdas. D.E.L.T.A., 9(1):

82-104. 1993

VOGT, Carlos; FRY, Peter. Cafundó: a África no Brasil: linguagem e sociedade. São Paulo: Companhia das Letras. 1996.

ZILLES, Ana Maria Stahl. Ainda os equívocos no combate aos estrangeirismos. In:FARACO, Carlos Alberto (org). Estrangeirismos: guerras em torno da língua. São Paulo: Parábola editorial. $2^{\text {a }}$ edição. 2002 